\title{
Induced Abortion and Associated Factors in Health Facilities of Guraghe Zone, Southern Ethiopia
}

\author{
Gezahegn Tesfaye, ${ }^{1}$ Mitiku Teshome Hambisa, ${ }^{1}$ and Agumasie Semahegn ${ }^{2}$ \\ ${ }^{1}$ Department of Public Health, College of Health and Medical Sciences, Haramaya University, P.O. Box 235, Harar, Ethiopia \\ ${ }^{2}$ School of Nursing and Midwifery, College of Health and Medical Sciences, Haramaya University, P.O. Box 235, Harar, Ethiopia \\ Correspondence should be addressed to Gezahegn Tesfaye; gezites@gmail.com
}

Received 11 December 2013; Revised 24 February 2014; Accepted 27 February 2014; Published 30 March 2014

Academic Editor: Fabio Facchinetti

Copyright (c) 2014 Gezahegn Tesfaye et al. This is an open access article distributed under the Creative Commons Attribution License, which permits unrestricted use, distribution, and reproduction in any medium, provided the original work is properly cited.

\begin{abstract}
Unsafe abortion is one of the major medical and public health problems in developing countries including Ethiopia. However, there is a lack of up-to-date and reliable information on induced abortion distribution and its determinant factors in the country. This study was intended to assess induced abortion and associated factors in health facilities of Guraghe zone, Southern Ethiopia. Institution based cross-sectional study was conducted in eight health facilities in Guraghe zone. Client exit interview was conducted on 400 patients using a structured questionnaire. Bivariate and multivariate logistic regression analysis was performed to identify factors associated with induced abortion. Out of 400 women, $75.5 \%$ responded that the current pregnancy that ended in abortion is unwanted. However, only $12.3 \%$ of the respondents have admitted interference to the current pregnancy. Having more than four pregnancies $(\mathrm{AOR}=4.28, \mathrm{CI}:(1.24-14.71))$, age of $30-34$ years $(\mathrm{AOR}=0.15, \mathrm{CI}:(0.04-0.55))$, primary education $(\mathrm{AOR}=0.26, \mathrm{CI}$ : $(0.13-0.88))$, and wanted pregnancy $(\mathrm{AOR}=0.44, \mathrm{CI}:(0.14-0.65))$ were found to have association with induced abortion. The study revealed high level of induced abortion which is underpinned by high magnitude of unwanted pregnancy. There is requirement for widespread expansion of increased access to high quality family planning service and post-abortion care.
\end{abstract}

\section{Introduction}

World Health Organization (WHO) defines unsafe abortion as a procedure for terminating unwanted pregnancy either by people lacking the necessary skills or in an environment lacking minimal medical standards or both [1]. According to WHO, worldwide unsafe abortions were estimated to be 21.6 million, almost all in developing countries. Each year, throughout the world, approximately 210 million women became pregnant and around one in 10 pregnancies ends in an unsafe abortion. The estimated annual number of unsafe abortions in Sub-Saharan Africa is 5.5 million. Although unsafe abortions are preventable, they continue to pose undue risks to a woman's health [2].

Millennium Development Goal (MDG) 5, announced in 2001 , is an internationally agreed-upon imperative to reduce maternal mortality by $75 \%$ from its 1990 level by the year 2015. As a significant proportion of mortality is due to unsafe abortion, this goal probably cannot be met without specific and direct programmatic efforts to reduce the impact of unsafe abortion [3].

Unsafe abortion accounts for 13\% of maternal deaths worldwide and as much as $25 \%$ in some countries [4]. Over $40 \%$ of the total deaths due to unsafe abortion have occurred in Africa making it the leading cause of maternal mortality in the region [5]. The maternal mortality ratio (MMR) in Ethiopia was estimated at 676 deaths per 100,000 live births in the year 2011 [6]. It is estimated that there are 3.27 million pregnancies in Ethiopia every year, of which approximately 500,000 end in either spontaneous or induced abortion [7].

In 2005, Ethiopia expanded its abortion law, which had previously allowed the procedure only to save the life of a woman or protect her physical health. Currently abortion is legal in Ethiopia under certain preconditions that include cases of rape, incest or fetal impairment, if the pregnancy endangers her or her child's life, or if continuing the pregnancy or giving birth endangers her life. A woman may also terminate a pregnancy if she is unable to bring up the child, 
owing to her status as a minor or to a physical or mental infirmity. Despite the implementation of the new law, almost six in ten abortions in Ethiopia are unsafe [8].

Reasons for resorting to unsafe abortion after unwanted or unplanned pregnancy were well established and reflected the status of women in the society. Some of the reasons are inability to support self and family, having already enough children, being very young, and being in school [9-11]. Lack of access to adequate family planning services is a major contributor to the global problem of unsafe abortion. A woman seeking treatment for incomplete abortion already may have experienced an unwanted pregnancy either as a result of not using contraception or method failure [12].

A nationally representative survey conducted in Ethiopia in 2008 revealed that an estimated 382,000 induced abortions were performed and 52,600 women were treated for complications of abortion. The annual abortion rate was 23 per 1,000 women aged 15-44 years and the abortion ratio was 13 per 100 live births, about $42 \%$ of pregnancies were unintended, and the unintended pregnancy rate was 101 per 1,000 women [13]. Another hospital based study in Ethiopia revealed $50 \%$ unwanted pregnancies and $25.6 \%$ induced abortion. Fifty-eight percent of the women who induced abortion terminated the current pregnancy either by seeking the help of untrained personnel or by themselves with no assistance [14]. A survey conducted in Harar, Eastern Ethiopia, showed $33.3 \%$ unintended pregnancies while induced abortion was found to be $14.4 \%$ [15].

Unsafe abortion is one of the greatest neglected problems of health care in developing countries and is a major medical and public health problem in Ethiopia [6]. Nevertheless, lack of up-to-date and reliable information on induced abortion distribution and its determinant factors has partly hindered the progress towards alleviating the problem in the country. Thus, the aim of this study was to assess induced abortion and associated factors in health facilities of Guraghe zone, southern Ethiopia.

\section{Methods and Materials}

2.1. Study Area and Period. The study was conducted in health facilities of Guraghe zone, southern Ethiopia. Guraghe zone is one of the 13 zones in the Southern Nations, Nationalities, and Peoples Region (SNNPR). Its capital Welkite is located $156 \mathrm{~km}$ south west of Addis Ababa along the road from Addis Ababa to Jimma. The zone is divided into 13 administrative woredas with an estimated total population of 1.7 million. According to the zonal health bureau, the zone has 26 health centers, one zonal public hospital, two nongovernmental hospitals, and one Family Guidance Association (FGA) clinic. Eleven health facilities have already initiated post-abortion care services (two hospitals and nine health centers) in the zone. Eight health facilities (two hospitals and six heath centers) were included in the study. The study was conducted from January to March, 2010.

2.2. Study Design. The study employed facility-based cross-sectional study design. Facility based study was preferred because health facility is the most logical, costeffective, and convenient place to conduct research on unsafe abortion where women with complications of unsafe abortion are treated despite having its own limitations [16].

2.3. Source Population. All women who received postabortion care service in health facilities of Guraghe zone were included.

\subsection{Study Subjects}

2.4.1. Inclusion Criteria. All women who received postabortion care during the study period in the 8 selected health facilities were included in the study.

2.4.2. Exclusion Criteria. Those patients who were unable to hear, mentally disabled, seriously sick, and were not volunteer to participate and patients whose gestational age was greater than 28 weeks were excluded from the study.

\subsection{Sampling}

2.5.1. Sample Size Determination. The sample size was calculated based on the following assumptions: proportion of patients who seek post-abortion care $(P=50 \%)$ taken to get the maximum sample size, $Z=1.96$ at $95 \%$ confidence interval, $d=$ the level of precision (0.05), and non-response rate $=10 \%$; then the total sample size for this study became 422.

2.5.2. Sampling Procedure. All consecutively discharged cases from the selected health facilities during the study period were included in the study until the required sample was obtained for each heath facility as determined based on their patient load as recommended by WHO [16].

2.6. Data Collection Method and Tool. Interviewer administered structured questionnaire was used to collect the data. The questionnaire was developed after extensive review of similar studies done previously and adapted to the purpose of the study. The types of questions asked include "sociodemographic data," "reproductive health history," "reproductive intentions," and "fertility control." The questions were translated into local language and administered by the interviewers in a careful way so as to keep the patient at ease and in a manner showing respect to their opinion in a nonjudgmental approach. Information about induced abortion was elicited from the study participants by using the question "is the current abortion after an attempt to terminate the pregnancy?" and asking them to explain about "why (reason) they resort to induced abortion," "the condition under which the induced abortion was performed," and so forth. The data collectors were female diploma nurses. The clients were interviewed after discharge was decided and just before the client left the respective health institution as exit interview. 


\subsection{Study Variables}

Dependent Variable. Induced abortion which refers to "postabortion patients who admitted interference to terminate their pregnancy intentionally either on their own or by another person."

Independent Variables. Independent variables include the following:

(i) sociodemographic variables;

(ii) reproductive history (current pregnancy (wanted versus unwanted), previous abortions, and number of pregnancies).

2.8. Data Entry and Analysis. After collection of the data the responses were coded and entered into EPI Info version 3.5.1. Data were cleaned and then exported to SPSS version 15 for windows for analysis. Then, the frequency distribution of dependent and independent variables was worked out. A crude and adjusted odds ratio from bivariate and multivariate analyses was used to measure association between dependent and independent variables. Those variables which were found to be significant in the bivariate analysis at $P$ value $<0.05$ were taken to logistic regression model for further multivariate analysis. Then, logistic regression analysis was done to control confounding variables and to identify independent factors associated with induced abortion. Participants were allocated to cases (those having induced abortion) based on their response, so those who have admitted that the abortion is because of interference were allocated to "cases" and those who deny it as "noncases" in the logistic regression analysis.

2.9. Data Quality Assurance. The English version questionnaire was translated into local language Amharic and again back to English so as to ensure its consistency. The translated Amharic version was pretested in a health facility other than the selected facilities in 5\% of the sample size that were not part of the main study. Modification was made on omitted, an unanswerable, or unclear questions accordingly. Supervisors daily check completeness, clarity, and consistency of the questionnaire. The data collectors and supervisors were trained by the principal investigator on the objectives of the study and how to make the interview, fill the questionnaire, and handle questions asked by clients during interviewing for three days.

\section{Results}

3.1. Sociodemographic Characteristics. A total of 422 patients were identified and 400 women participated in the study making the response rate $95 \%$. Majority, 193 (48.25\%), of the respondents were aged between 20 and 29 years. The mean age of the respondents was 25.3 years $(\mathrm{SD} \pm 6.4)$. About half, 227 (56.8\%), of the participants were married, $130(32.5 \%)$ were illiterate, and 185 (46.3\%) were housewives (Table 1).

3.2. Reproductive History, Family Planning Knowledge, and Practice. About 207 (51.8) of the respondents have history of one or two pregnancies including the current pregnancy
TABLE 1: Sociodemographic characteristics of postabortion patients in health institutions of Guraghe zone, South Ethiopia, from January to March, 2010.

\begin{tabular}{|c|c|c|}
\hline Variables $(n=400)$ & Number & Percentage (\%) \\
\hline \multicolumn{3}{|l|}{ Age (mean $25.3(\mathrm{SD} \pm 6.4))$} \\
\hline $15-19$ & 91 & 22.75 \\
\hline $20-24$ & 99 & 24.75 \\
\hline $25-29$ & 94 & 23.5 \\
\hline $30-34$ & 66 & 16.5 \\
\hline $35+$ & 50 & 12.5 \\
\hline \multicolumn{3}{|l|}{ Marital status } \\
\hline Married & 227 & 56.8 \\
\hline Single & 160 & 40 \\
\hline Divorced & 9 & 2.3 \\
\hline Widowed & 4 & 1 \\
\hline \multicolumn{3}{|l|}{ Occupational status } \\
\hline House wife & 185 & 46.3 \\
\hline Student & 134 & 33.5 \\
\hline Daily laborer & 29 & 7.3 \\
\hline Office worker & 21 & 5.3 \\
\hline Teacher & 9 & 2.3 \\
\hline Commercial sex worker & 8 & 2 \\
\hline House maid & 7 & 1.8 \\
\hline Others & 7 & 1.8 \\
\hline \multicolumn{3}{|l|}{ Educational status } \\
\hline Illiterate & 130 & 32.5 \\
\hline Read and write & 46 & 11.5 \\
\hline Primary education & 99 & 24.8 \\
\hline Secondary education & 87 & 21.8 \\
\hline Tertiary education & 38 & 9.5 \\
\hline \multicolumn{3}{|l|}{ Ethnic group } \\
\hline Guraghe & 319 & 79.8 \\
\hline Amhara & 46 & 11.5 \\
\hline Oromo & 23 & 5.8 \\
\hline Others & 12 & 3 \\
\hline \multicolumn{3}{|l|}{ Religion } \\
\hline Orthodox & 166 & 41.5 \\
\hline Muslim & 182 & 45.5 \\
\hline Protestant & 39 & 9.8 \\
\hline Catholic & 13 & 3.3 \\
\hline
\end{tabular}

that ended in abortion. The majority, 185 (46.5\%), of the patients have no history of delivery. Sixty-eight (17\%) of the respondents had previous history of abortion, which was experienced once in $86.8 \%$, twice in $11.7 \%$, and three times in $1.5 \%$ of the respondents. The majority, 302 (75.5\%), of the post-abortion patients revealed that the current pregnancy which ended in abortion was unwanted while the remaining ninety-eight (24.5\%) of the patients said it is wanted. Fortynine $(12.3 \%)$ of the patients admitted interference with the current pregnancy (Table 2).

The majority of those who reported their last pregnancy as unwanted stated partner pressure and negligence to take contraceptives regularly as main reasons for the pregnancy. 
TABLE 2: Reproductive history of postabortion clients in health institutions of Guraghe zone, South Ethiopia, from January to March, 2010.

\begin{tabular}{|c|c|c|}
\hline Variables $(n=400)$ & Frequency & Percentage \\
\hline \multicolumn{3}{|c|}{ Number of pregnancies ${ }^{* *}$} \\
\hline$<2$ & 207 & 51.8 \\
\hline $3-5$ & 128 & 32 \\
\hline $6-8$ & 61 & 15.2 \\
\hline 9 and above & 4 & 1 \\
\hline \multicolumn{3}{|l|}{ Delivery } \\
\hline None & 185 & 46.3 \\
\hline 1 & 40 & 10 \\
\hline $2-4$ & 130 & 32.5 \\
\hline $5-7$ & 43 & 11.25 \\
\hline 8 and above & 2 & 0.5 \\
\hline \multicolumn{3}{|l|}{ Previous abortion } \\
\hline Yes & 68 & 17 \\
\hline No & 332 & 83 \\
\hline \multicolumn{3}{|c|}{ Frequency of previous abortion (68) } \\
\hline Once & 59 & 86.8 \\
\hline Twice & 8 & 11.7 \\
\hline Three times & 1 & 1.5 \\
\hline \multicolumn{3}{|c|}{ Current pregnancy wanted } \\
\hline Yes & 98 & 24.5 \\
\hline No & 302 & 75.5 \\
\hline \multicolumn{3}{|c|}{ Current pregnancy induced/interfered } \\
\hline Yes & 49 & 12.3 \\
\hline No & 351 & 87.7 \\
\hline
\end{tabular}

Among those who admitted interference to the current pregnancy reported place of interference as health institutions, patient's home, and inducer's house, 25 (51\%), 22 (45\%), and 2 (4\%), respectively. Materials used to induce the pregnancy were herbs, 18 (36.7\%); plastics, 15 (30.6\%); and different medications in $11(22.4 \%)$ of the patients. Twenty $(40.8 \%)$ reported that interference was done by themselves followed by health workers, 25 (51\%) (Table 3). Main reasons given for resorting to induced abortion by those who admitted interference were to complete education, 20 (40.8\%), and for economic reasons, 18 (36.7\%) (Figure 1$)$.

Two hundred eighty-two (70.5\%) of the study participants knew at least one family planning method, the most commonly known being oral contraceptive pills. Two hundred forty three $(60.8 \%)$ of the participants have used contraceptive at least once in their life time. When seen by type of abortion, 33 (67.3\%) of those who admitted interference and $210(69.5 \%)$ of those with spontaneous abortion reported use of contraceptive at least once in their life time.

3.3. Fertility Awareness, Pregnancy Intention, and Receiving Family Planning Method. Majority of the clients, 123 (30.8\%), stated that fertility will return within one month, $162(40.5 \%)$ never want to be pregnant in the future, only $226(56.5 \%)$ got post-abortion family planning method, and the most
TABLE 3: Reasons for unwanted pregnancy, place and methods of interference to the current pregnancy among post abortion clients in health institutions of Guraghe zone, South Ethiopia, from January to March, 2010.

\begin{tabular}{|c|c|c|}
\hline Variables & Number & Percent \\
\hline \multicolumn{3}{|l|}{ Reason for unwanted pregnancy (302) } \\
\hline Contraceptive failure & 47 & 15.6 \\
\hline Forget to take contraceptives & 102 & 33.8 \\
\hline Partner pressure & 122 & 40.4 \\
\hline Do not know contraceptives & 31 & 10.3 \\
\hline \multicolumn{3}{|l|}{$\begin{array}{l}\text { Place of interference to current pregnancy } \\
(n=49)\end{array}$} \\
\hline Health institutions & 25 & 51 \\
\hline Patient's house & 22 & 45 \\
\hline Inducers house & 2 & 4 \\
\hline \multicolumn{3}{|l|}{ Method used for interference } \\
\hline Plastic & 15 & 30.6 \\
\hline Medication (oral, vaginal and injection) & 16 & 32.7 \\
\hline Herbs & 18 & 36.7 \\
\hline \multicolumn{3}{|l|}{ Doer of induced abortion } \\
\hline Health workers & 25 & 51 \\
\hline Traditional birth attendant & 4 & 8.2 \\
\hline Self & 20 & 40.8 \\
\hline \multicolumn{3}{|l|}{ Sex of who assisted patient } \\
\hline Male & 17 & 58.6 \\
\hline Female & 10 & 34.5 \\
\hline Not reported & 2 & 6.9 \\
\hline
\end{tabular}
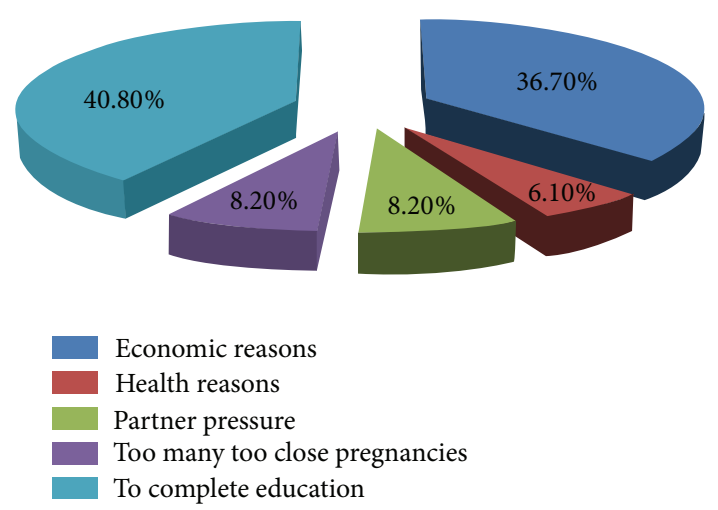

FIGURE 1: Reasons for interference with the current pregnancy among post-abortion clients in Guraghe zone, south Ethiopia, from January to March, 2010.

common reason for not getting family planning method was, 96 (24\%), refusal and, 47 (11.8\%), not counseled family planning (Table 4$)$.

3.4. Factors Associated with Induced Abortion. In the bivariate analysis, educational status and number of pregnancies are associated with induced abortion. In multivariate analysis, those patients who have greater than four pregnancies were 
TABLE 4: Fertility awareness, pregnancy intentions, and family planning method provision among postabortion patients in health institution of Guraghe zone, South Ethiopia, from January to March, 2010.

\begin{tabular}{|c|c|c|}
\hline Variables & Number & Percentage \\
\hline \multicolumn{3}{|l|}{$\begin{array}{l}\text { Patient opinion on fertility return after } \\
\text { abortion }\end{array}$} \\
\hline Within two weeks & 98 & 24.5 \\
\hline One month & 123 & 30.8 \\
\hline Three months & 110 & 27.5 \\
\hline Six months & 57 & 14.3 \\
\hline Above six months & 10 & 2.5 \\
\hline No response & 2 & 0.5 \\
\hline \multicolumn{3}{|l|}{ Future pregnancy plan } \\
\hline Never & 162 & 40.5 \\
\hline Within three months & 70 & 17.5 \\
\hline Within two years & 18 & 4.5 \\
\hline Above two years & 131 & 33.1 \\
\hline No response & 18 & 4.5 \\
\hline \multicolumn{3}{|l|}{ Got FP method } \\
\hline Yes & 226 & 56.5 \\
\hline No & 174 & 43.5 \\
\hline \multicolumn{3}{|l|}{ Reasons for not getting FP } \\
\hline No one raised the issue & 47 & 11.8 \\
\hline Changed my mind & 96 & 24.0 \\
\hline Referral & 9 & 2.3 \\
\hline Other health reasons & 3 & 0.8 \\
\hline Contraceptives were not available & 19 & 4.8 \\
\hline
\end{tabular}

NB: FP = family planning.

more likely to have induced abortion than those who have less than four pregnancies $(\mathrm{AOR}=4.28, \mathrm{CI}=(1.24-14.71))$ and those patients who reported that they want the current pregnancy were less likely to have induced abortion $(\mathrm{AOR}=0.44$, CI: (0.14-0.65)) than those who do not want their current pregnancy. In addition, those patients who were in primary school and age group 30-34 were less likely to have induced abortion $(\mathrm{AOR}=0.26$, $\mathrm{CI}:(0.13-0.88))$ and $(\mathrm{AOR}=0.15$, CI: $(0.04-0.55))$ (Table 5).

\section{Discussion}

In this study the magnitude of induced abortion was $12.3 \%$. The main reasons for induced abortion were to complete education, $40.8 \%$, and economic reason, $36.7 \%$. More than threefourth, $75.5 \%$, of the current pregnancies were unwanted. Partner pressure and forgetting to take contraceptives were the main reasons mentioned for unwanted pregnancy. About $40.5 \%$ of the clients never want to be pregnant at all. More than half, 51\%, of the induced abortions took place in health institution by health workers. Age 30-34 years, primary education, number of pregnancies, and wanted pregnancy had association with induced abortion.
Even though, $75.5 \%$ reported current pregnancy was unwanted in this study; only $12.3 \%$ admitted that the pregnancy was interfered. According to WHO, distinguishing between spontaneous and induced abortion among women who received care in health facility is difficult. Since women fear retribution or inadequate care, they are likely to deny unsafe procedures even in the face of the most obvious evidence. Therefore, WHO classified those women who admitted the pregnancy interference in the certainly induced abortion category and those women who states that the pregnancy was unwanted but denied interference in the category of possibly induced abortion [16]. As a result the magnitude of induced abortion may be underestimated. In general this is a sensitive area that respondents do not want to disclose. Due to this fact results from different studies show varying number of proportions between spontaneous and induced abortions. A study conducted in Isfahan, central Iran, revealed a similar result; $12 \%$ of the patients reported induced abortion [17]. Another study conducted in northwest Ethiopia revealed $4.8 \%$ prevalence rate of induced abortion which is much lower than our study [18], implying that induced abortion is a hidden public health problem affecting the reproductive health outcome status of women.

The current study finding shows partner pressure and negligence to take contraceptives as a main cause for the unwanted pregnancies which is similar to other studies [11, 19] in that contraceptive misuse or poor knowledge are the main cause for unwanted pregnancies. These facts show how the low socio-economic status of women in the community affects their decision making that risks their life temporarily or permanently. Women still lack the autonomy to make decisions about their pregnancy intention. As is the case with many other areas of reproductive health, husbands appear to be the primary decision-makers with regard to pregnancy. Furthermore, the main reasons for resorting to induced abortion in this study (economic reason and to complete education) were not different from the work of previous investigators [11, 20, 21].

In our study, $40.5 \%$ of the clients never want to be pregnant which is higher than study conducted in Addis Ababa where only $31.7 \%$ never want to become pregnant at all [19]. The number of women who want to limit pregnancy is still high in both studies which imply that there is a high family planning demand to space or limit their next pregnancy calling that post-abortion setting continues to be an important opportunity to provide post-abortion family planning counseling and initiate family planning methods.

The fact that $51 \%$ of the induced abortion was undertaken in health institutions by health workers might be due to the flareup of private clinics which leads to management in substandard settings and poor professional competence of health workers. According to a study in Mekelle, northern Ethiopia [21], health professionals undertook the inductions in $82.7 \%$ which is even much higher than this study. A study in Dare Selaam showed that most (79\%) abortions had been induced at clinic or hospital (43.6\%) by health care workers [22].

This study showed that being in primary school, age 3034 years, having more than 4 children, and wanted pregnancy 
TABLE 5: Factors associated with induced abortion in health institutions of Guraghe zone, South Ethiopia from January to March 2010.

\begin{tabular}{|c|c|c|c|c|}
\hline \multirow{2}{*}{ Variables } & \multicolumn{2}{|c|}{ Induced abortion } & \multirow{2}{*}{ COR $(95 \% \mathrm{CI})$} & \multirow{2}{*}{ AOR (95\% CI) } \\
\hline & Yes & No & & \\
\hline \multicolumn{5}{|l|}{ Age } \\
\hline $15-19$ & 12 & 79 & 1 & 1 \\
\hline $20-24$ & 11 & 88 & $1.22(0.51-2.91)$ & $0.91(0.36-2.26)$ \\
\hline $25-29$ & 11 & 83 & $1.15(0.48-2.75)$ & $0.63(0.20-1.97)$ \\
\hline $30-34$ & 11 & 55 & $0.75(0.53-5.73)$ & $0.15(0.04-0.55)^{*}$ \\
\hline $30+$ & 4 & 46 & $1.75(0.53-5.73)$ & $0.31(0.06-1.54)$ \\
\hline \multicolumn{5}{|l|}{ Marital status } \\
\hline Married & 25 & 202 & 1 & 1 \\
\hline Single & 24 & 149 & $0.77(0.42-1.40)$ & $1.351(0.58-3.14)$ \\
\hline \multicolumn{5}{|l|}{ Education } \\
\hline Illiterate & 10 & 120 & 1 & 1 \\
\hline Read and write & 9 & 37 & $0.34(0.13-0.91)^{*}$ & $0.35(0.12-1.01)$ \\
\hline Primary (1-8th) & 16 & 83 & $0.43(0.19-1.00)^{*}$ & $0.26(0.13-0.88)^{*}$ \\
\hline Secondary and above & 14 & 109 & $0.44(0.18-1.04)$ & $0.28(0.08-1.01)$ \\
\hline \multicolumn{5}{|l|}{ Occupation } \\
\hline Employed & 2 & 35 & 1 & 1 \\
\hline Unemployed & 47 & 316 & $0.38(0.09-1.65)$ & $1.33(0.11-15.51)$ \\
\hline \multicolumn{5}{|l|}{ Religion } \\
\hline Christians & 44 & 268 & 1 & 1 \\
\hline Muslims & 5 & 83 & 1.07 (0.58-1.95) & $1.18(0.60-2.34)$ \\
\hline \multicolumn{5}{|l|}{ Current pregnancy } \\
\hline Unwanted & 42 & 390 & 1 & 1 \\
\hline Wanted & 7 & 61 & $2.10(0.91-4.84)$ & $0.44(0.14-0.65)^{*}$ \\
\hline \multicolumn{5}{|l|}{ Previous abortion } \\
\hline No & 42 & 260 & 1 & 1 \\
\hline Yes & 7 & 91 & $1.26(0.54-2.94)$ & $1.17(0.39-3.48)$ \\
\hline \multicolumn{5}{|l|}{ Number of pregnancy } \\
\hline Less than 4 & 44 & 268 & 1 & 1 \\
\hline Greater than 4 & 5 & 83 & $2.73(1.05-7.10)^{*}$ & $4.28(1.24-14.71)^{*}$ \\
\hline
\end{tabular}

${ }^{*}$ Significant at $95 \%$ Confidence level.

had association with induced abortion. Being in primary education is protective of induced abortion in this study. A study in north west Ethiopia showed a different result in that as the level of education increased there was an increase in the number of mothers who had induced abortion, particularly those who had a high school education were highly exposed to induced abortion [18]. This may be due to the fact that children in primary school were living with their family under strict parental supervision which prevents them from unwanted pregnancy which ends up with induced abortion.

Age 30-34 years $[\mathrm{AOR}=0.15$, (CI 0.04-0.55)] was negatively associated with induced abortion. A study done in Ghana [23] also showed the same result in which women with induced abortions were significantly within younger age groups. This might be due to the fact that women at this age group will be economically independent, in a stable marital relationship, and have completed their education unlike the younger age groups.

Clients having greater than 4 children $[\mathrm{AOR}=4.28$, $(\mathrm{CI}$ 1.24-14.71)] were 4 times more likely to commit induced abortion. This finding is in line with a study in Spain [24] in which those clients who have some children were more likely to have induced abortion than those who have no children. This may be true because women who had several pregnancies would have the tendency not to have additional children so they may tend to avoid unwanted pregnancies by inducing their current pregnancy.

Those patients who want the pregnancy $[\mathrm{AOR}=0.44$, (CI 0.14-0.65)] were less likely to have induced abortion. This finding is similar to another study conducted in Addis Ababa [19]. The immediate explanation for this is that a woman seeking induced abortion usually have unplanned or unwanted pregnancy which in turn is related to lack of wide spread information about family planning and its utilization.

Strength of this study is that it used primary data by directly interviewing the owners of the problem, whereas the limitation of the study is that since abortion is a sensitive issue and legally restricted in Ethiopia, patient interviews may introduce social desirability bias which may result in under reporting. 


\section{Conclusion}

Generally, the study revealed a high level of induced abortion. Unwanted pregnancy is high among abortion patients in the study area. Educational level, age of the patient, number of pregnancy, and whether or not the pregnancy is wanted were factors significantly associated with induced abortion. Increased access to high-standard family planning service, post-abortion care, strict counseling about family planning method reminder, and partner involvement in family planning service should be emphasized.

\section{Ethical Approval}

Ethical approval was obtained from Haramaya University, institutional research ethics review committee (IRERC). A letter of cooperation was written to respective bodies. Informed consent was obtained from each study participant. Patients who were not willing to continue from the beginning or from any part of the interview had the right to withdraw. Anonymity was maintained by avoiding personal identifier information and privacy was kept by conducting the interview in a separate place.

\section{Conflict of Interests}

The authors would like to declare that they have no conflict of interests in this study.

\section{Authors' Contribution}

Gezahegn Tesfaye conceived the study, carried out the overall design and execution of the study, performed data collection and statistical analysis, and participated in the drafting of the paper. Mitiku Teshome Hambisa and Agumasie Semahegn participated in the critical revision of the design of the study and data collection techniques, helped in the statistical analysis, and participated in the drafting and critical revision of the paper for publication. All authors read and finally approved this paper for publication.

\section{Acknowledgments}

The authors would like to extend their sincere thanks to Haramaya University and Ethiopian Ministry of Education for funding the research. The authors would like to extend their special thanks to all data collectors, supervisors, and study participants.

\section{References}

[1] WHO, Safe and Unsafe Induced Abortion Global and Regional Levels in 2008, and Trends During 1995-2008, World Health Organization, Geneva, Switzerland.

[2] WHO, Unsafe Abortion Global and Regional Estimates of the Incidence of Unsafe Abortion and Associated Mortality in 2008, World Health Organization, Geneva, Switzerland, 6th edition, 2011.
[3] C. Shannon and B. Winikoff, "Unsafe abortion and strategies to reduce its impact on women's lives," chapter 9, pp. 149, 2010.

[4] Family planning: a key component of post abortion care Consensus Statement: International Federation of Gynecology and Obstetrics (FIGO), International Confederation of Midwives (ICM), International Council of Nurses (ICN), and (USAID), 2009.

[5] WHO, Unsafe Abortion, Global and Regional Estimates of Incidence of Mortality Due to Unsafe Abortion with a Listing of Available Country Data, World Health Organization, Geneva, Switzerland, 2004.

[6] CSA and ORC Macro, Ethiopia Demographic and Health Survey 2011, Central Statistical Agency and ORC Macro, Addis Ababa, Ethiopia and Calverton, Md, USA, 2012.

[7] Technical and Procedural Guidelines For Safe Abortion Services in Ethiopia, Ministry of Health, Addis Ababa, Ethiopia, 2006.

[8] Facts on Unintended Pregnancy and Abortion in Ethiopia, IPAS, Guttmacher institute, New York, NY, USA, 2010.

[9] A. Justesen, S. H. Kapiga, and H. A. G. A. van Asten, "Abortions in a hospital setting: hidden realities in Dar es Salaam, Tanzania," Studies in Family Planning, vol. 23, no. 5, pp. 325-329, 1992.

[10] W. Judith, O. Elizabeth, and M. Noel, "post-abortion care, a reference manual for improving quality of Care," post-abortion Care Consortium, pp. 9.1-9.16, 1995.

[11] F. Hassen, Analysis of Factors for Unwanted Pregnancy among Women in Reproductive Age Group Attending Health Institutions in Jimma Town, Unpublished Report, 2000.

[12] post-abortion Care Consortium Community Task Force. Essential Elements of post-abortion Care: an Expanded and Updated Model. post-abortion Care Consortium, 2002.

[13] S. Singh, T. Fetters, H. Gebreselassie et al., "The estimated incidence of induced abortion in Ethiopia, 2008," International Perspectives on Sexual and Reproductive Health, vol. 36, no. 1, pp. $16-25,2010$.

[14] M. Tekle-Ab, G. Yirgu, and F. Misganaw, "Survey of unsafe abortion in selected health facilities in Ethiopia," Ethiopian Journal of Reproductive Health, vol. 1, no. 1, pp. 28-43, 2007.

[15] S. Worku and M. Fantahun, "Unintended pregnancy and induced abortion in a town with accessible family planning services: the case of Harar in eastern Ethiopia," Ethiopian Journal of Health Development, vol. 20, no. 2, pp. 79-83, 2006.

[16] WHO, Studying Unsafe Abortion: A practical Guide, Maternal and Newborn Health, Safe Motherhood, Division of Reproductive Health, World Health Organization, Geneva, Switzerland, 1994.

[17] F. Majlessi, A. R. Forooshani, and M. Shariat, "Prevalence of induced abortion and associated complications in women attending hospitals in Isfahan," Eastern Mediterranean Health Journal, vol. 14, no. 1, pp. 103-109, 2008.

[18] E. Senbeto, G. Alene, N. Anbeso, and H. Yeneneh, "Prevalence and associated risk factors of induced abortion in northwest Ethiopia," Ethiopian Medical Journal, vol. 19, no. 1, pp. 37-44, 2005.

[19] M. Yilma, E. Fikre, A. Ahmed, G. Hailemichael, and Y. Lukman, "Fertility awareness and post abortion pregnancy intention in Addis Ababa, Ethiopia," Ethiopian Journal of Health Development, vol. 17, no. 3, pp. 167-174, 2003.

[20] C. V. Mote, E. Otupiri, and M. J. Hindin, "Factors associated with induced abortion among women in Hohoe, Ghana," African Journal of Reproductive Health, vol. 14, no. 4, pp. 115121, 2010. 
[21] G. B. Abera, B. Berhanu, A. B. Kahsay, H. B. Gebru, and A. Aregay, "Assessment of determinants of induced abortion among child bearing age women attending maternal and child health clinic in Mekelle town, Tigray, Ethiopia: a cross sectional study," International Journal of Pharmaceutical Sciences and Research, vol. 3, no. 12, pp. 4745-4756, 2012.

[22] R. Vibeke, M. Hamed, U. Ernest, and B. Staffan, “The problem of illegally induced abortion: results from a hospital-based study conducted at district level in Dar es Salaam," Tropical Medicine and International Health, vol. 5, no. 7, pp. 495-502, 2000.

[23] H. M. Schwandt, A. A. Creanga, K. A. Danso, R. M. K. Adanu, T. Agbenyega, and M. J. Hindin, "A comparison of women with induced abortion, spontaneous abortion and ectopic pregnancy in Ghana," Contraception, vol. 84, no. 1, pp. 87-93, 2011.

[24] D. O. Tsakiridu, A. F. Vidal, F. V. Valdés et al., "Factors associated with induced abortion in women prostitutes in Asturias (Spain)," PLoS ONE, vol. 3, no. 6, Article ID e2358, 2008. 


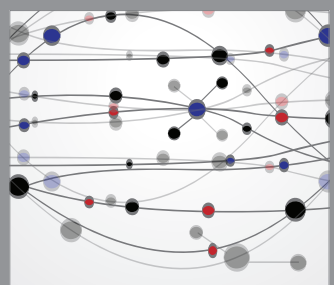

The Scientific World Journal
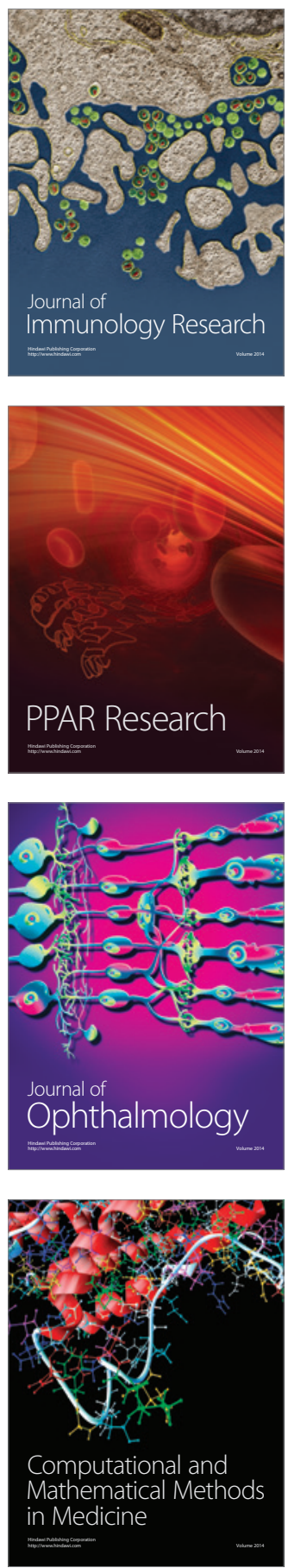

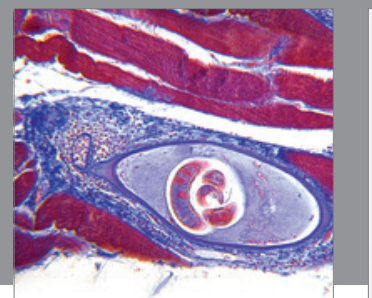

Gastroenterology

Research and Practice
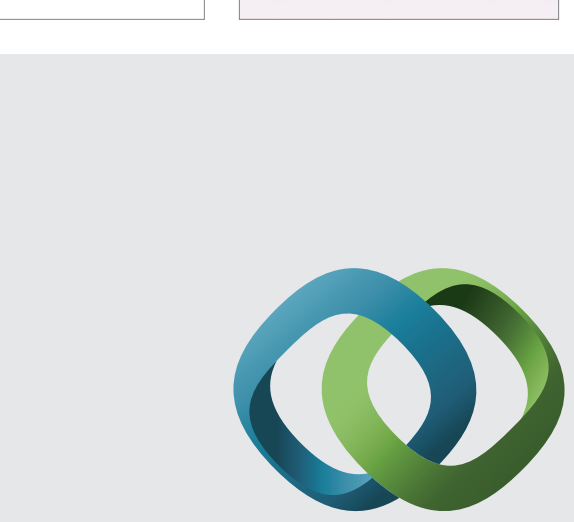

\section{Hindawi}

Submit your manuscripts at

http://www.hindawi.com
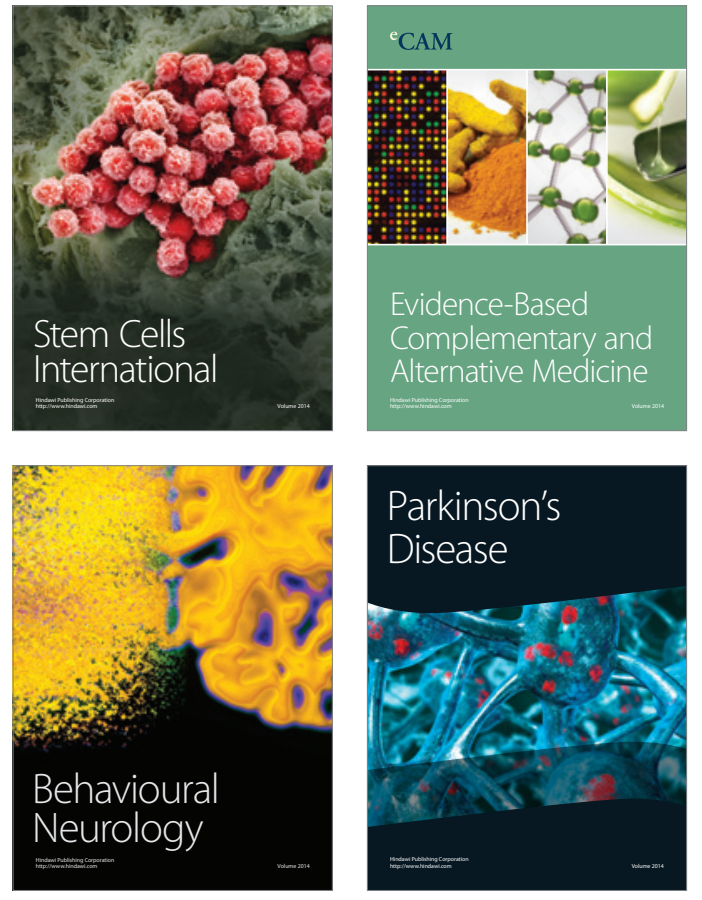
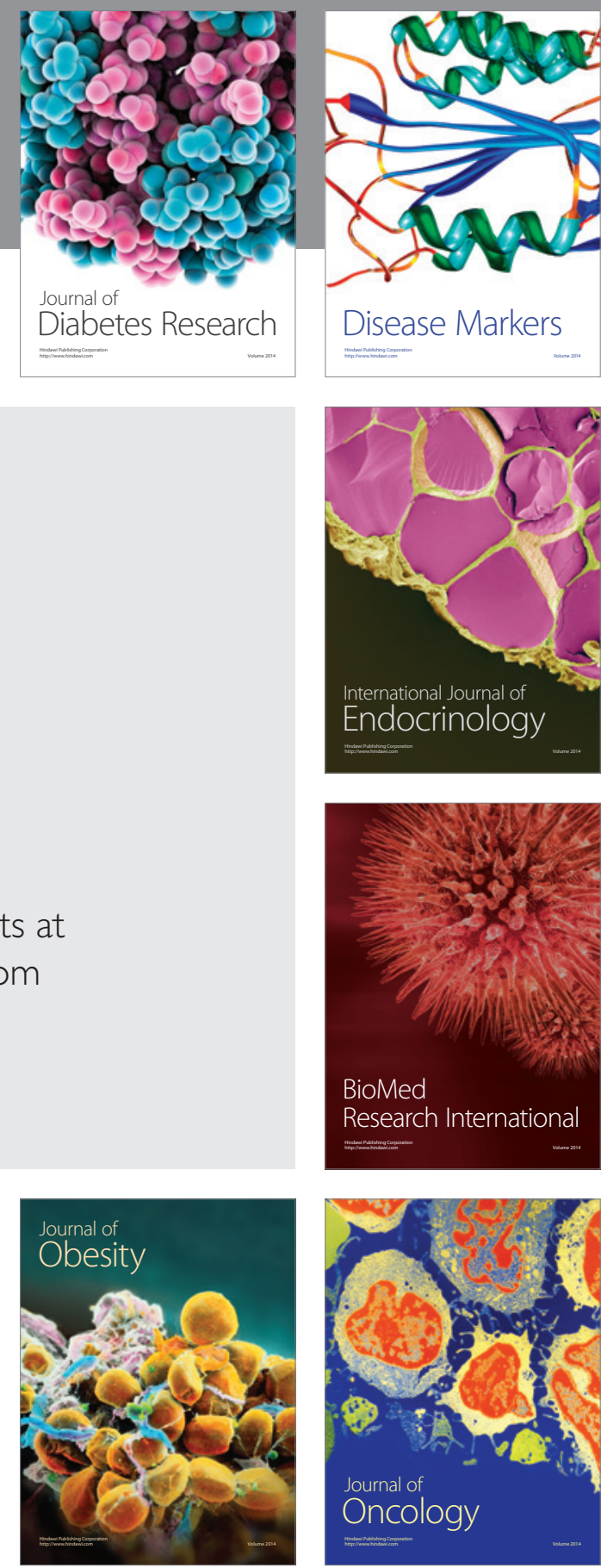

Disease Markers
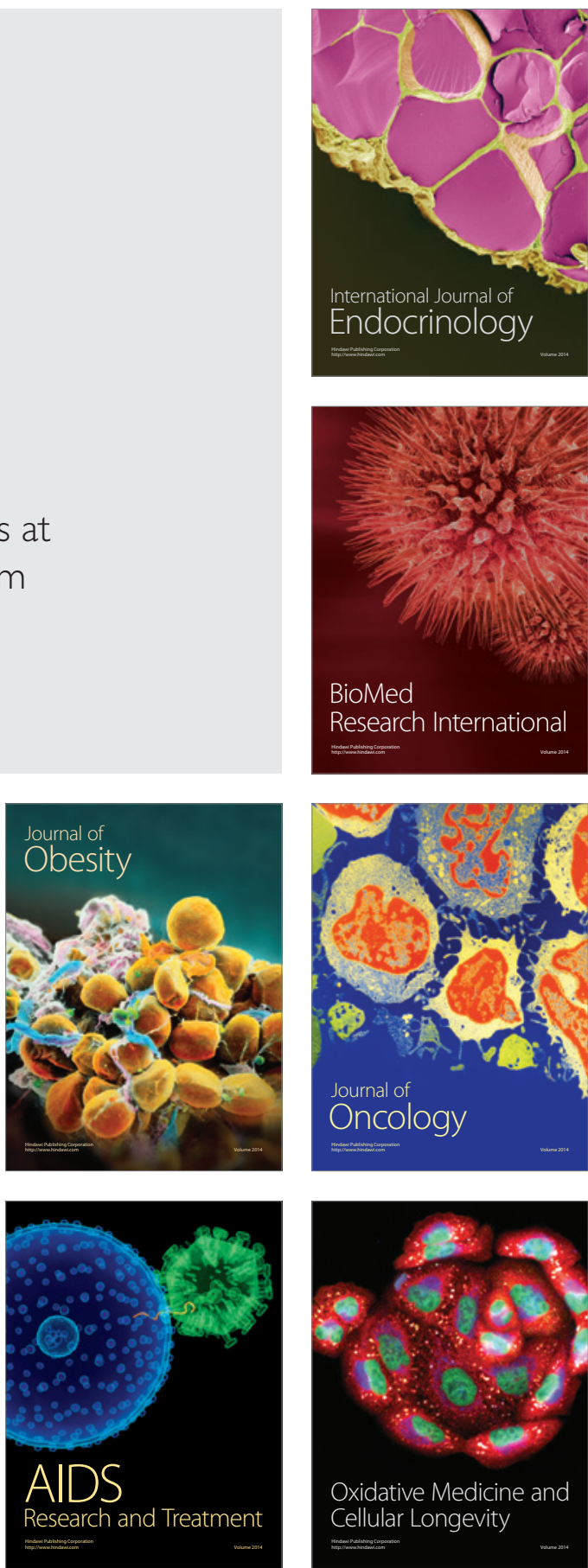